\title{
Quantifying microcalcification activity in the thoracic aorta
}

\author{
Alexander J. Fletcher, $M B C h B,{ }^{a}$ Maria Lembo, $M D,{ }^{a, b}$ Jacek Kwiecinski, MD, ${ }^{c}$ \\ Maaz B. J. Syed, $M B C h B,{ }^{a}$ Jennifer Nash, $M B C h B,{ }^{d}$ Evangelos Tzolos, $M D,{ }^{a}$ \\ Rong Bing, MBBS, , Sebastien Cadet, MS, ${ }^{\text {e }}$ Gillian MacNaught, PhD, ${ }^{\text {a,g }}$ \\ Edwin J. R. van Beek, MD, PhD, ${ }^{\mathrm{a}, \mathrm{g}}$ Alistair J. Moss, PhD, ${ }^{\mathrm{a}}$ Mhairi K. Doris, \\ MBChB, ${ }^{a}$ Niki L. Walker, MD, PhD, ${ }^{\mathrm{a}, \mathrm{h}}$ Damini Dey, PhD, ${ }^{\mathrm{e}}$ Philip D. Adamson, MD,

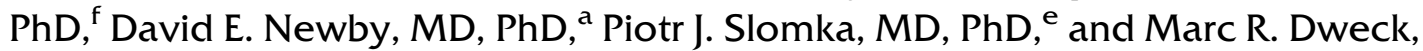 \\ $M D, P h D^{a}$ \\ a British Heart Foundation Centre for Cardiovascular Science, University of Edinburgh, Edinburgh, \\ UK \\ b Department of Advanced Biomedical Sciences, Federico II University of Naples, Naples, Italy \\ c Department of Interventional Cardiology and Angiology, Institute of Cardiology, Warsaw, \\ Poland \\ d Department of Vascular Surgery, Queen Elizabeth University Hospital, Glasgow, UK \\ e Department of Imaging (Division of Nuclear Cardiology), Cedars-Sinai Medical Centre, Los \\ Angeles \\ f Christchurch Heart Institute, University of Otago, Christchurch, New Zealand \\ g Edinburgh Imaging Facility, Queens Medical Research Institute, University of Edinburgh, \\ Edinburgh, UK \\ h Scottish Adult Congenital Cardiology Service, Golden Jubilee National Hospital, Clydebank, \\ Glasgow, UK
}

Received Sep 7, 2020; accepted Nov 17, 2020

doi: 10.1007/s12350-020-02458-w

Background. Standard methods for quantifying positron emission tomography (PET) uptake in the aorta are time consuming and may not reflect overall vessel activity. We describe aortic microcalcification activity (AMA), a novel method for quantifying ${ }^{18} \mathrm{~F}$-sodium fluoride $(18 \mathrm{~F}-\mathrm{NaF})$ uptake in the thoracic aorta.

Electronic supplementary material The online version of this article (https://doi.org/10.1007/s12350-020-02458-w) contains supplementary material, which is available to authorized users.

The authors of this article have provided a PowerPoint file, available for download at SpringerLink, which summarises the contents of the paper and is free for re-use at meetings and presentations. Search for the article DOI on SpringerLink.com.

The authors have also provided an audio summary of the article, which is available to download as ESM, or to listen to via the JNC/ASNC Podcast.

Funding AJF (FS/19/15/34155), MBJS (FS/18/31/33676), NLW (FS/ 19/15/34155), RB (PG/19/40/34422), ET (FS/17/51/33096) and DEN (FS/19/15/34155, CH/09/002, RG/16/10/32375, RE/18/5/ 34216) are supported by the British Heart Foundation. DEN is also the recipient of a Wellcome Trust Senior Investigator Award (WT103782AIA). AJM is supported by the British Heart Foundation (AA/18/3/34220). MRD is supported by the British Heart Foundation $(\mathrm{FS} / 14 / 78 / 31020)$ and is the recipient of the Sir Jules Thorn Award for Biomedical Research 2015 (15/JTA). EJRVB is supported by SINAPSE (www.sinapse.ac.uk). PDA is supported by a Heart Foundation of New Zealand Senior Fellowship (1844). PS, SC and FusionQuant Development is supported by the National Institute of Health Grant HL135557 (PI: Piotr Slomka). ML is supported by the International $\mathrm{PhD}$ programme in Cardiovascular Pathophysiology and Therapeutics (CardioPaTh).

Reprint requests: Alexander J. Fletcher, $\mathrm{MBChB}$, British Heart Foundation Centre for Cardiovascular Science, University of Edinburgh, Edinburgh; afletch4@ed.ac.uk $1071-3581 / \$ 34.00$

Copyright (C) 2021 The Author(s) 
Methods. Twenty patients underwent two hybrid ${ }^{18}$ F-NaF PET and computed tomography (CT) scans of the thoracic aorta less than three weeks apart. AMA, as well as maximum (TBRmax) and mean (TBRmean) tissue to background ratios, were calculated by two trained operators. Intra-observer repeatability, inter-observer repeatability and scan-rescan reproducibility were assessed. Each ${ }^{18} \mathrm{~F}$-NaF quantification method was compared to validated cardiovascular risk scores.

Results. Aortic microcalcification activity demonstrated excellent intra-observer (intraclass correlation coefficient $\mathbf{0 . 9 8}$ ) and inter-observer (intraclass correlation coefficient 0.97) repeatability with very good scan-rescan reproducibility (intraclass correlation coefficient 0.86 ) which were similar to previously described TBRmean and TBRmax methods. AMA analysis was much quicker to perform than standard TBR assessment (3.4min versus $15.1 \mathrm{~min}$, $P<0.0001)$. AMA was correlated with Framingham stroke risk scores and Framingham risk score for hard cononary heart disease.

Conclusions. AMA is a simple, rapid and reproducible method of quantifying global ${ }^{18} \mathrm{~F}$ $\mathrm{NaF}$ uptake across the ascending aorta and aortic arch that correlates with cardiovascular risk scores. (J Nucl Cardiol 2022;29:1372-85.)

Key Words: PET $\cdot$ Modalities $\cdot$ Image analysis $\cdot$ Technical $\cdot$ Molecular imaging agents • Tracers $\cdot$ Others $\cdot$ Tests

\begin{tabular}{|ll|}
\hline \multicolumn{2}{|l|}{ Abbreviations } \\
${ }^{18} \mathrm{~F}-\mathrm{NaF}$ & Sodium fluoride \\
AMA & Aortic microcalcification activity \\
$\mathrm{CT}$ & computed tomography \\
$\mathrm{PET}$ & Positron emission tomography \\
SUV & standardised uptake value \\
TBR & Tissue to background ratio \\
TBR $_{\text {MDS }}$ & Most diseased segment tissue to back- \\
& ground ratio \\
\hline
\end{tabular}

See related editorial, pp. 1386-1388

\section{INTRODUCTION}

Thoracic aortic calcification is an important pathological entity underlying both intimal atherosclerotic disease and medial degenerative processes. ${ }^{1}$ High-density macro-calcified lesions in the aortic wall can be readily identified using computed tomography $(\mathrm{CT})$ and are associated with an increased risk of stroke and mortality. ${ }^{1-4}$ However, these lesions represent a late and stable stage of vascular wall pathology where active disease processes may have become quiescent. ${ }^{5}$ In contrast, microcalcification - typically defined as lesions $<50 \mu \mathrm{m}$ - cannot be detected on conventional imaging but can identify regions of active vascular disease., ${ }^{18} \mathrm{~F}$-Sodium fluoride $\left({ }^{18} \mathrm{~F}-\mathrm{NaF}\right)$ is a positron emitting radiotracer that allows the detection of microcalcification activity by positron emission tomography (PET), ${ }^{8}$ providing a marker of aortic disease which might further improve risk prediction. Indeed, coronary ${ }^{18} \mathrm{~F}-\mathrm{NaF}$ PET has recently demonstrated its ability to improve risk prediction beyond that afforded by CT calcium score. ${ }^{9,10}$ Thus, there is interest in developing summary quantitative methods of measuring ${ }^{18} \mathrm{~F}-\mathrm{NaF}$ uptake in the aorta, which may provide similarly important prognostic information.

Quantification of ${ }^{18} \mathrm{~F}$-sodium fluoride uptake in the thoracic aorta currently involves labour intensive analysis of multiple regions of interest across sequential axial slices and calculating mean and maximum intensity uptake values. These values are then normalized to blood pool activity to generate mean (TBRmean) and maximum (TBRmax) tissue to background ratios respectively. ${ }^{11-13}$ Typically, TBRmax values are influenced by only a small number of the most intense pixels within a volume of interest and may not accurately reflect the overall PET activity within that volume (Figure 1). A simple, robust and time-efficient technique that could provide a summary measure of PET uptake across the thoracic aorta would be a major advance. We, therefore, aimed to develop a novel method of quantifying the burden of ${ }^{18} \mathrm{~F}-\mathrm{NaF}$ uptake across both the ascending aorta and aortic arch (aortic microcalcification activity, AMA) and to assess its repeatability, reproducibility and time-efficiency compared with current standard approaches. Finally, we provide a comparison between each method and well validated clinical risk scores for future risk of cardiovascular events. ${ }^{14,15}$

\section{METHODS}

\section{Study Population}

Twenty patients recruited as part of the Dual antiplatelet therapy to Inhibit Atherosclerosis and Myocardial Injury in patients with Necrotic high-risk coronary plaque Disease (DIAMOND NCT02110303) study underwent two hybrid ${ }^{18} \mathrm{~F}-\mathrm{NaF}$ PET-CT scans of the thoracic aorta no more than three weeks apart. ${ }^{16,17}$ 


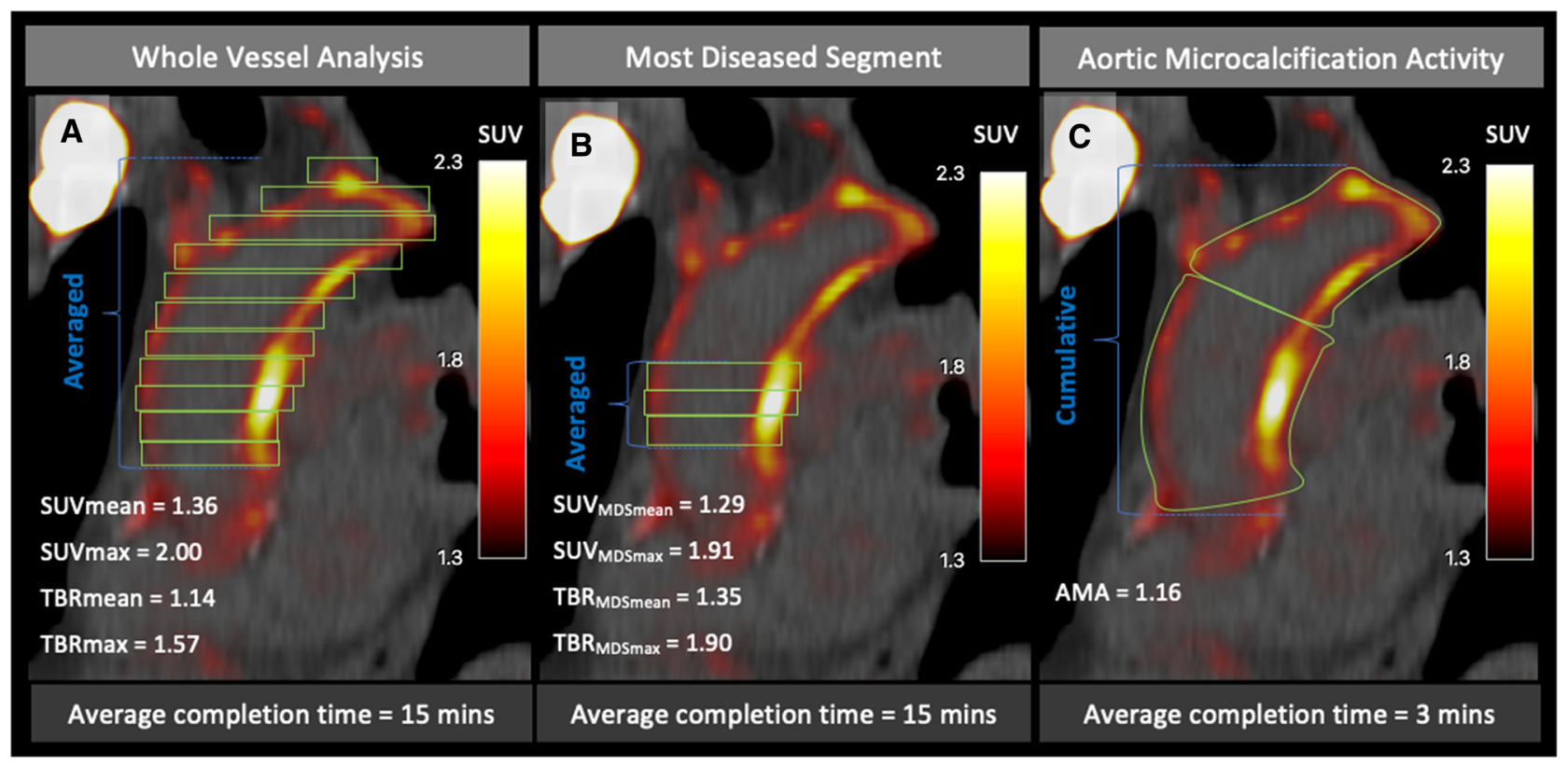

Figure 1. ${ }^{18}$ F-Sodium fluoride positron emission tomography and computed tomography in a patient with marked aortic wall uptake. An illustrated representation of standard whole vessel (A) and most diseased segment (B) as well as novel aortic microcalcification $(\mathbf{C})$ methods for quantifying uptake. Average time taken to complete each method is shown. AMA, aortic microcalcification activity; Asc, ascending aorta; $C T$, computed tomography; $P A$, pulmonary artery; $P E T$, positron emission tomography; $L V$, left ventricle; $R A$, right atrium; $T B R$, tissue to background ratio.

Inclusion criteria for the study were patients $\geq 40$ years old with angiographically confirmed multivessel coronary disease defined as epicardial vessels with $>50 \%$ stenosis or having undergone previous coronary revascularisation. Exclusion criteria included acute coronary syndrome in the preceding 12 months, revascularisation in the preceding 3 months, estimated glomerular filtration rate $<30 \mathrm{~mL} / \mathrm{min} / 1.73 \mathrm{~m}^{2}$, concurrent therapy with oral anticoagulants or thienopyridine (clopidogrel or prasugrel), or known allergy to iodine contrast media. The study was approved by the local institutional review board, the Scottish Research Ethics Committee (REC reference: 14/SS/0089), the Medicines and Healthcare products Regulatory Agency, and the United Kingdom Administration of Radiation Substances Advisory Committee and written informed consent was acquired from all patients. The present work is a post-hoc analysis of this prospective randomised controlled trial.

\section{PET-CT Image Acquisition Protocol}

All scans were performed 60 min after injection of $250 \mathrm{MBq}$ of ${ }^{18} \mathrm{~F}-\mathrm{NaF}$ on a hybrid PET-CT scanner (128multidetector Biograph mCT, Siemens Medical Systems, Erlangen, Germany) at a single centre. Attenuation correction CT was performed immediately before PET data acquisition (100-120 kV, current 40-50 mA), and reconstructed at 3-mm slice thickness. The field of view incorporated the heart and whole thoracic aorta including the first branches of the head and neck vessels. PET data were acquired with ECG-gating in list-mode during a single 30-min bed position.

\section{Positron Emission Tomography Reconstruction}

PET images were reconstructed into four cardiac phases. All PET image reconstructions were performed using the UHD algorithm which applies point-spread function and time-of-flight techniques on a $256 \times 256$ matrix (109 slices, slice thickness $2.027 \mathrm{~mm}$ ) using 2 iterations, a 5-mm Gauss filter and 21 subsets. Initial analysis was performed by analysing uptake throughout the cardiac cycle (summed gate). However, we have demonstrated improved repeatability and reproducibility with correction for heart movement and blood pool clearance when assessing coronary arteries. ${ }^{18}$ As such, motion-corrected images of the ascending aorta and arch were also obtained applying the same custom-built algorithm as used in the coronary vessels for quantifying PET uptake (FusionQuant v1.20.05.14, Cedars-Sinai 
Medical Centre, Los Angeles). ${ }^{19}$ This motion correction function aligns the aortic uptake from all gates throughout the cardiac cycle onto the mid-diastolic gate without data loss. Finally correction for blood pool clearance and the time interval between ${ }^{18} \mathrm{~F}-\mathrm{NaF}$ injection and scan acquisition were performed as described previously and applied to the background (blood-pool) activity. ${ }^{20}$

\section{Assessment of Aortic ${ }^{18}$ F-Sodium Fluoride Uptake}

Conventional methods for assessing aortic uptake were investigated alongside AMA using FusionQuant v1.20 software as described below (Cedars-Sinai Medical Centre, Los Angeles). ${ }^{21}$ For all the methods, the PET signal was first carefully co-registered in 3 orthogonal planes using the non-contrast attenuation $\mathrm{CT}$ in all patients. Background activity in the blood pool was determined as the average standardised uptake value (SUVmean) of two $2-\mathrm{cm}^{3}$ spheres of interest, one in the right atrium and one in the left atrium. The time to complete image analysis was recorded for all of the methods investigated.

Aortic microcalcification activity measurements We modified the recently published technique for assessing global ${ }^{18} \mathrm{~F}-\mathrm{NaF}$ uptake across the coronary $\operatorname{arteries}^{22,23}$ for use in the ascending aorta and aortic arch. Aortic ${ }^{18} \mathrm{~F}-\mathrm{NaF}$ activity was measured within volumes of interest created around the aorta using a centreline function in a multiplanar reconstruction viewer (Figure 2). The final diameter of the ROI around the aorta was equal to the maximal luminal diameter of the aorta of that section plus $4 \mathrm{~mm}$ (the approximate spatial resolution of PET). This margin of error can be consistently drawn and was added because the spatial resolution of PET is limited, PET and CT may be misregistered, and tracer uptake is frequently highest around the outer perimeter of the vessel. The ascending aortic volume of interest started at the sinotubular junction and finished immediately proximal to the junction with the brachiocephalic artery. The aortic arch volume of interest started at the junction with the brachiocephalic artery and finished immediately distal to the junction with the left subclavian artery. The descending aorta was not quantified during this analysis due to overspill of ${ }^{18} \mathrm{~F}-\mathrm{NaF}$ uptake originating from the adjacent thoracic spine.

Aortic microcalcification activity (AMA) represents the ratio of aortic activity to background radiotracer activity. Aortic activity is calculated by taking the cumulative voxel intensity in the aortic volumes of interest and dividing by the volume in $\mathrm{cm}^{3}$, to give aortic intensity per $\mathrm{cm}^{3}$. The background radiotracer activity is similarly calculated by dividing the cumulative
४Figure 2. Step-by-step outline of measuring aortic microcalcification activity. (A) Co-register register 18F-sodium fluoride overlay to computed tomography image in three orthogonal planes using landmarks of the sternum, spine, and aortic wall (blue arrows). $(\mathbf{B}+\mathbf{C})$ Place a $2 \mathrm{~cm}^{3}$ region of interest in the centre of the right $(\mathbf{B})$ and left $(\mathbf{C})$ atrium. The background activity is the cumulative SUV per $\mathrm{cm}^{3}$ from the volumes of interest in the left and right atrium. (D, F) With the ${ }^{18} \mathrm{~F}$-sodium fluoride overlay turned off, a centreline function is used to draw the ascending aortic volume of interest in multiplanar reconstruction images. Perpendicular to the aorta, the volume of interest starts at the sinotubular junction (D) and finishes at the slice just proximal to the origin of the brachiocephalic artery $(\mathbf{E})$. The width of the volume of interest is increased to the maximum ascending aortic diameter $+4 \mathrm{~mm}(\mathbf{F}+\mathbf{H})$. The ${ }^{18} \mathrm{~F}$-sodium fluoride overlay is reinstated to ensure good coverage (I). The ascending aortic AMA, and volume are calculated (I). The aortic arch volume of interest is drawn with the same method as the ascending aorta, starting with the slice immediately distal to the ascending aortic volume of interest $(\mathbf{J})$, and finishing with the slice after the origin of the left subclavian artery $(\mathbf{K})$. The width of the aortic arch volume of interest is increased to the maximal arch dimeter $+4 \mathrm{~mm}(\mathbf{M}$ $+\mathbf{N})$. The ${ }^{18} \mathrm{~F}$-sodium fluoride overlay is reinstated to check good coverage and calculate the aortic arch AMA and volume (N). (O) Provides the formula for calculating overall AMA, whilst $(\mathbf{P})$ uses the values in the current case to provide a working example of AMA calculation.

radiotracer activity in the two $2-\mathrm{cm}^{3}$ atrial volumes of interest, and dividing by the volume, giving background voxel intensity per $\mathrm{cm}^{3}$ (Figure 2). AMA is calculated by dividing aortic intensity per $\mathrm{cm}^{3}$ by background intensity per $\mathrm{cm}^{3}$ as a unitless number. Contamination from the sternum or clavicular bones was excluded by applying an upper voxel intensity limit to the AMA. This threshold is set at the SUVmax in a volume of interest out-with the sternum, excluding all values above it in calculations of AMA.

Whole vessel standardised uptake values and tissue to background ratios Established methods for calculating whole vessel SUVmean and SUVmax were applied using methodology for the ascending aorta and aortic arch described previously. ${ }^{12,24}$ Briefly, on adjacent axial images, A series of 2-D regions of interest were drawn around the aorta on adjacent 3-mm slices beginning where the right pulmonary artery is first visible, finishing at the last slice in which the aortic arch is visible. The average SUVmean and SUVmax over all regions of interest (typically between 30 and 40 slices) were calculated (Figure 1). Tissue to background ratios (TBRs) were also calculated for each region of interest - performed by dividing SUVmean and SUVmax values by blood pool activity (TBRmean and TBRmax, respectively). TBR values were similarly averaged over all regions of interest for whole vessel TBRmean and TBRmax. 


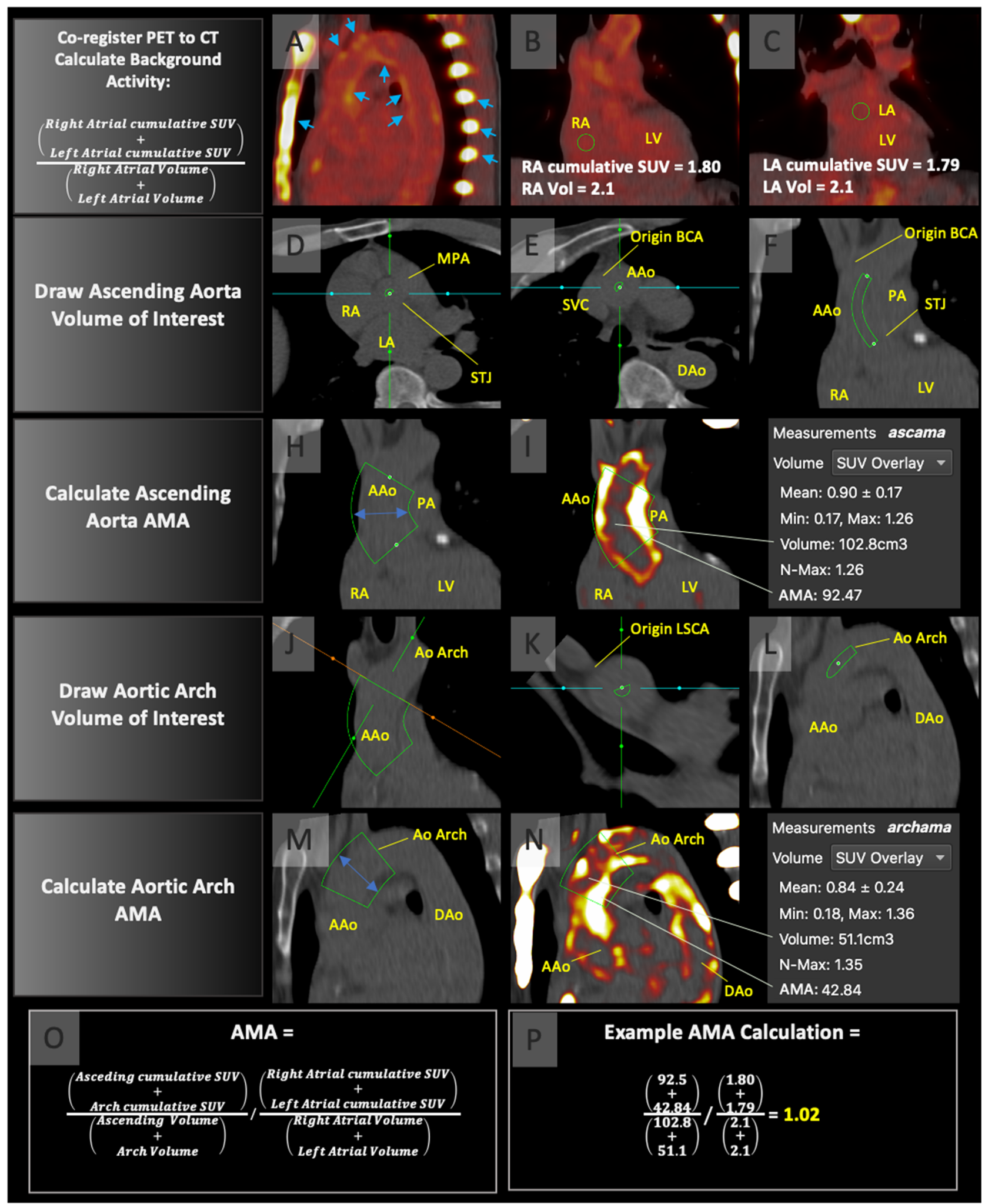


Table 1. Patient characteristics

\begin{tabular}{|c|c|}
\hline Characteristic & $\begin{array}{c}\text { Mean } \pm \text { Standard } \\
\text { Deviation or Number } \\
(\%)\end{array}$ \\
\hline Age (years) & $70 \pm 7$ \\
\hline Female sex & $3(15 \%)$ \\
\hline Type II diabetes mellitus & $2(10 \%)$ \\
\hline $\begin{array}{l}\text { Normal estimated } \\
\text { glomerular filtration } \\
\text { rate* }\end{array}$ & $17(85 \%)$ \\
\hline $\begin{array}{l}\text { Body-mass Index (kg/ } \\
\left.\mathrm{m}^{2}\right)\end{array}$ & $27 \pm 4$ \\
\hline \multicolumn{2}{|l|}{ Smoking status } \\
\hline Current & $3(15 \%)$ \\
\hline Ex-smoker & $14(70 \%)$ \\
\hline Never & $3(15 \%)$ \\
\hline Hypertension & $14(70 \%)$ \\
\hline Hypercholesterolaemia & $20(100 \%)$ \\
\hline $\begin{array}{l}\text { Previous myocardial } \\
\text { infarction }\end{array}$ & $13(65 \%)$ \\
\hline $\begin{array}{l}\text { Previous stroke or } \\
\text { transient ischaemic } \\
\text { attack }\end{array}$ & $1(5 \%)$ \\
\hline \multicolumn{2}{|l|}{$\begin{array}{l}\text { Previous } \\
\text { revascularisation }\end{array}$} \\
\hline $\begin{array}{l}\text { Coronary artery bypass } \\
\text { graft }\end{array}$ & $9(45 \%)$ \\
\hline Coronary stenting & $13(65 \%)$ \\
\hline \multicolumn{2}{|l|}{ Medication } \\
\hline Statin & $20(100 \%)$ \\
\hline Beta-blocker & $9(45 \%)$ \\
\hline $\begin{array}{l}\text { Angiotensin- } \\
\text { converting enzyme } \\
\text { inhibitor }\end{array}$ & 17 (85\%) \\
\hline Aspirin & $20(100 \%)$ \\
\hline $\begin{array}{l}\text { Left ventricular } \\
\text { hypertrophy on } \\
\text { electrocardiogram }\end{array}$ & $0(0 \%)$ \\
\hline
\end{tabular}

mean \pm standard deviation; $\mathrm{n}(\%)$

${ }^{*}>60 \mathrm{~mL} / \mathrm{min} / 1.73 \mathrm{~m}^{2}$

\footnotetext{
Most diseased segment standardized uptake values and tissue to background ratios As described previously, using the same regions of interest drawn in whole vessel analysis, the most diseased segment approach considers only the three consecutive regions of interest with the highest mean $\left(\mathrm{SUV}_{\text {MDSmean }}\right.$ and $\left.\mathrm{TBR}_{\text {MDSmean }}\right)$ and $\max \left(\mathrm{SUV}_{\text {MDSmax }}\right.$ and $\mathrm{TBR}_{\mathrm{MDSmax}}$ ) values and therefore represents uptake in the single most intense lesion. ${ }^{13,25}$
}

\section{Observer Repeatability and Scan-Rescan Reproducibility}

All baseline scans were interpreted by two trained observers (AF and ML) using all techniques described above (AMA, whole vessel analysis, most diseased segment). The 20 repeat scans were analysed for all methods by one of the trained observers (AF or ML), blinded to the original results, in a random order and more than 4 weeks after the first analysis of the baseline scans to minimise recall bias.

\section{Time Efficiency Analysis}

In 10 randomly selected cases, the time taken to conduct each method (whole vessel analysis, most diseased segment and AMA) were recorded separately. The time taken to measure blood pool activity was excluded from the analysis as this is common to all techniques.

\section{Clinical Correlation}

Framingham stroke risk score and Revised Framingham stroke risk score are validated risk scores for predicting the 10-year risk of stroke. ${ }^{15,26}$ Framingham risk score for hard coronary heart disease and American College of Cardiology/American Heart Association Atherosclerotic Cardiovascular Disease (ACC/AHA ASCVD) score are validated risk scores for predicting the 10-year risk of coronary events and cardiovascular events respectively. ${ }^{27,28}$ Each of these scores were calculated for each participant and the correlation with PET assessments of aortic ${ }^{18} \mathrm{~F}-\mathrm{NaF}$ activity investigated.

\section{Statistical Analysis}

All statistical analyses were performed in the opensource statistical software package R (V4.0.2). Continuous variables with normal distribution were presented as mean \pm standard deviation, whereas non-normally distributed variables were presented as median [interquartile range]. Categorical variables were presented as number (percentage). Intra- and inter-observer variability as well as scan-rescan reproducibility were assessed using for each ${ }^{18} \mathrm{~F}-\mathrm{NaF}$ aortic uptake method using mean error, $95 \%$ limits of agreement, coefficient of reproducibility, intraclass correlation coefficient and Bland-Altman plots. ${ }^{29}$ Associations between clinical risk scores and PET uptake methods were evaluated as a continuous variable (Pearson's correlation coefficient). Statistical significance was taken as a two-sided $P<0.05$. 


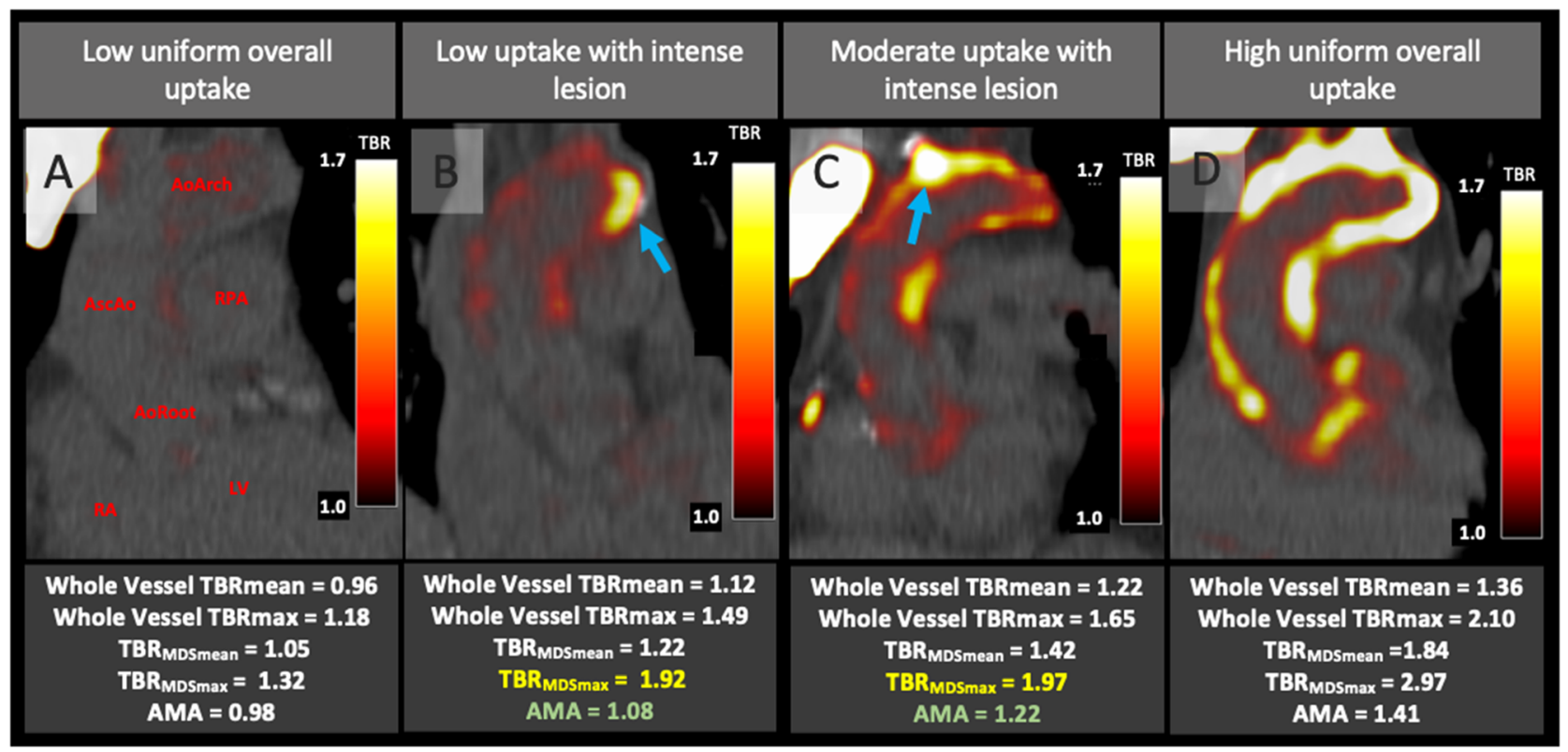

Figure 3. Hybrid ${ }^{18} \mathrm{~F}$-sodium fluoride positron emission tomography and computed tomography coronal images of the ascending aorta and arch in four patients with varying patterns and intensity of aortic wall ${ }^{18} \mathrm{~F}$ sodium fluoride activity: (A) Homogenously low activity across the ascending aorta and arch; (B) Generally low activity with a single high intensity lesion (blue arrow); (C) Moderate activity with a high intensity lesion (blue arrow); (D) High and intense activity throughout ascending aorta and arch. Note that (B) and (C) have similar values for most diseased segment maximum tissue to background ratio (highlighted in yellow) despite substantially different overall activity (aortic microcalcification activity values highlighted in green). AscAo, ascending aorta; AMA, aortic microcalcification activity; AoArch, aortic arch; AoRoot, aortic root; $M D S$, most diseased segment; $L V$, left ventricle; $R A$, right atrium; $R P A$, pulmonary artery; $S U V$, standardised uptake measurement; $T B R$, tissue to background ratio.

\section{RESULTS}

${ }^{18} \mathrm{~F}$-Sodium fluoride uptake was present in the ascending aorta and aortic arch of all twenty patients (Table 1). Uptake was seen in the aortic wall, although the pattern and degree of uptake varied markedly between patients (Figure 3). The AMA method was nearly 5 times quicker to perform than TBR analyses (3.4 \pm 0.5 versus $15.1 \pm 1.7 \mathrm{~min}, P<0.0001)$

\section{Intra-observer Repeatability of Aortic Microcalcification Activity}

The AMA values ranged from 0.91 to 1.51 with a mean of $1.08 \pm 0.14$. The intra-observer repeatability was excellent (intraclass correlation coefficient 0.98), with mean error $0.00,95 \%$ limits of agreement of -0.06 to 0.06 , and coefficient of repeatability of 0.05 . These results are similar to intra-observer repeatability for whole vessel and most diseased segment methods (Table 2, Supplementary Figure 1).

\section{Inter-observer Repeatability of Aortic Microcalcification Activity}

The inter-observer repeatability was excellent (intraclass correlation coefficient 0.97 ) with a mean error of 0.01 , narrow $95 \%$ limits of agreement of -0.05 to 0.07 , and a coefficient of repeatability of 0.08 (Table 2, Supplementary Figure 2). Again, similar inter-observer repeatabilities were seen for whole vessel and most diseased segment methods (Table 2, Supplementary Figure 2).

\section{Scan-Rescan Reproducibility of Aortic Microcalcification Activity}

The AMA method demonstrated very good scanrescan reproducibility (intraclass correlation coefficient 0.86 ) with a minimal mean error of 0.00 , narrow $95 \%$ limits of agreement of -0.13 to 0.13 , and a coefficient of reproducibility of 0.11 (Table 2, Figure 4). The scanrescan reproducibility of AMA was similar to the whole vessel TBRmean (intraclass correlation coefficient 0.84) and TBRmax (intraclass correlation coefficient 0.86 ) as well as most diseased segment $\mathrm{TBR}_{\mathrm{MDSmean}}$ (intraclass 
Table 2. Scan-rescan reproducibility, inter- and intra-observer reliability for whole vessel, most diseased segment and aortic microcalcification activity techniques

\begin{tabular}{|c|c|c|c|c|c|}
\hline & Range & Mean & $\begin{array}{l}\text { Mean Error } \\
(95 \% \text { LOA) }\end{array}$ & $\begin{array}{l}\text { Coefficient of } \\
\text { Repeatability } \\
\text { (\% of mean) }\end{array}$ & $\begin{array}{l}\text { Intraclass } \\
\text { Correlation } \\
\text { Coefficient } \\
\end{array}$ \\
\hline $\begin{array}{l}\text { Aortic microcalcification } \\
\text { activity }\end{array}$ & 0.91 to 1.51 & $1.08 \pm 0.14$ & & & \\
\hline Intra-observer & & & $\begin{array}{l}0.00 \\
(-0.06 \text { to } 0.06)\end{array}$ & $0.05(4 \%)$ & 0.98 \\
\hline Inter-observer & & & $\begin{array}{l}0.01 \\
(-0.05 \text { to } 0.07)\end{array}$ & $0.08(6 \%)$ & 0.97 \\
\hline Scan-rescan & & & $\begin{array}{l}-0.00 \\
(-0.13 \text { to } 0.13)\end{array}$ & $0.11(10 \%)$ & 0.86 \\
\hline Whole vessel TBRmean & 0.8 to 1.7 & $1.06 \pm 0.17$ & & & \\
\hline Intra-observer & & & $\begin{array}{l}0.00 \\
(-0.03 \text { to } 0.03)\end{array}$ & $0.03(3 \%)$ & 0.99 \\
\hline Inter-observer & & & $\begin{array}{l}-0.01 \\
(-0.16 \text { to } 0.15)\end{array}$ & $0.13(12 \%)$ & 0.87 \\
\hline Scan-rescan & & & $\begin{array}{l}0.01 \\
(-0.16 \text { to } 0.17)\end{array}$ & $0.17(16 \%)$ & 0.84 \\
\hline Whole vessel TBRmax & 1.0 to 2.6 & $1.42 \pm 0.33$ & & & \\
\hline Intra-observer & & & $\begin{array}{l}0.00 \\
(-0.03 \text { to } 0.04)\end{array}$ & $0.04(3 \%)$ & 0.99 \\
\hline Inter-observer & & & $\begin{array}{l}-0.02 \\
(-0.24 \text { to } 0.20)\end{array}$ & $0.17(12 \%)$ & 0.93 \\
\hline Scan-rescan & & & $\begin{array}{l}0.03 \\
(-0.26 \text { to } 0.33)\end{array}$ & $0.33(23 \%)$ & 0.86 \\
\hline $\begin{array}{l}\text { Most diseased segment } \\
\text { TBR }_{\text {MDSmean }}\end{array}$ & 0.97 to 2.14 & $1.21 \pm 0.25$ & & & \\
\hline Intra-observer & & & $\begin{array}{l}0.01 \\
(-0.04 \text { to } 0.05)\end{array}$ & $0.05(4 \%)$ & 0.99 \\
\hline Inter-observer & & & $\begin{array}{l}0.06 \\
(-0.14 \text { to } 0.26)\end{array}$ & $0.26(21 \%)$ & 0.94 \\
\hline Scan-rescan & & & $\begin{array}{l}0.02 \\
(-0.24 \text { to } 0.29)\end{array}$ & $0.30(25 \%)$ & 0.83 \\
\hline $\begin{array}{l}\text { Most diseased segment } \\
\text { TBR }_{\text {MDSmax }}\end{array}$ & 1.18 to 3.30 & $1.75 \pm 0.44$ & & & \\
\hline Intra-observer & & & $\begin{array}{l}0.00 \\
(-0.05 \text { to } 0.06)\end{array}$ & $0.06(3 \%)$ & 0.99 \\
\hline Inter-observer & & & $\begin{array}{l}0.07 \\
(-0.21 \text { to } 0.34)\end{array}$ & $0.34(19 \%)$ & 0.93 \\
\hline Scan-rescan & & & $\begin{array}{l}0.03 \\
(-0.34 \text { to } 0.40)\end{array}$ & $0.39(22 \%)$ & 0.90 \\
\hline
\end{tabular}

$L O A$, limits of agreement; $M D S$, most diseased segment; $S D$, standard deviation; $S U V$, standardized uptake value; $T B R$, tissue to background ratio; $T B R_{M D S m e a n}$, most diseased segment tissue to background ratio mean, $T B R_{M D S m a x}$ most diseased segment tissue to background ratio maximum 
correlation coefficient 0.83 ) and $\mathrm{TBR}_{\text {MDSmax }}$ (intraclass correlation coefficient 0.90, Table 2 and Figure 4).

Scan-rescan reproducibility was unaffected by correction for either the time from radiotracer injection to PET imaging or aortic motion during the cardiac cycle (Table 3). The AMA scores were highly co-linear with the other methods, particularly TBRmax (Supplementary Figure 5).

\section{Correlation to Clinical Risk Score for Stroke}

There was a moderate and positive correlation between AMA and the Framingham stroke risk score ( $R=0.50, P=0.03$, Figure 5), Revised Framingham stroke risk score $(R=0.44, P=0.05)$ and Framingham risk Score for hard coronary $(R=0.44, P=0.05$, Table 4). Apparent weaker associations were observed between the other PET measures and Framingham stroke risk score (Figure 5) and revised Framingham stroke risk score (Table 4). As well as AMA, most diseased segment TBRmax demonstrated a moderate correlation with Framingham risk score for hard coronary heart disease $(R=0.48, P=0.03)$. No risk scores correlated with the American College of Cardiology/ American Heart Association atherosclerotic cardiovascular score (ACC/AHA ASCVD, Table 4).

\section{DISCUSSION}

Molecular imaging techniques are increasingly being used for investigating disease activity in the cardiovascular system. We describe a novel method,
Figure 4. Scan-rescan reproducibility. Bland-Altmann plots with mean error (blue line) and 95\% limits of agreement (red lines) for whole vessel standardized uptake value mean (A), standardized uptake value max (B), tissue to background ratio mean $(\mathbf{C})$, tissue to background ratio max (D), most diseased segment tissue to background ratio mean (E) and tissue to background ratio maximum $(\mathbf{F})$ and aortic microcalcificaion activity (G) methods. Y-axis limits are set to the method mean value of the method concerned. $A M A$, aortic microcalcification activity; $C R$, coefficient of reproducibility; $I C C$, intraclass correlation coefficient, $M D S$, most diseased segment; $L O A$, limits of agreement; $S D$, standard deviation; $T B R$, tissue to background ratio.

AMA, which quantifies ${ }^{18} \mathrm{~F}-\mathrm{NaF}$ across both the ascending aorta and aortic arch, providing a measure of overall burden of disease activity in these vessels. We demonstrate this method as being highly reproducible and more time efficient than the whole vessel technique. Moreover, it can be performed with a non-contrast CT, and does not require advanced post-processing techniques, such as motion or time-delay correction, making it potentially more widely applicable. Finally, out of all methods assessed, AMA had the strongest correlation with Framingham stroke risk score and the revised Framingham stroke risk score. These results pave the way for future research investigating whether AMA holds advantages in terms of tracking disease progression and response to therapy as well as improving the prognostic performance of aortic PET.

There are several conceptual advantages to providing a more global assessment of ${ }^{18} \mathrm{~F}-\mathrm{NaF}$ activity across the aorta than is provided by standard approaches. The

Table 3. Influence of motion and background correction on aortic microcalcification activity scanrescan reproducibility

\begin{tabular}{|c|c|c|c|c|}
\hline & Range & $\begin{array}{c}\text { Mean } \\
\text { error } \\
(95 \% \\
\text { LOA) }\end{array}$ & $\begin{array}{l}\text { Coefficient of } \\
\text { reproducibility }\end{array}$ & $\begin{array}{c}\text { Intraclass correlation } \\
\text { coefficient }\end{array}$ \\
\hline AMA & $\begin{array}{c}0.91 \text { to } \\
1.51\end{array}$ & $\begin{array}{l}0.00 \\
(-0.13 \text { to } \\
0.13)\end{array}$ & $0.11(10 \%)$ & 0.86 \\
\hline $\begin{array}{l}\text { AMA + time-delay } \\
\text { correction }\end{array}$ & $\begin{array}{c}0.90 \text { to } \\
1.51\end{array}$ & $\begin{array}{l}0.00 \\
(-0.13 \text { to } \\
0.14)\end{array}$ & $0.12(11 \%)$ & 0.85 \\
\hline $\begin{array}{l}\mathrm{AMA}+\text { motion } \\
\text { correction }\end{array}$ & $\begin{array}{c}0.90 \text { to } \\
1.51\end{array}$ & $\begin{array}{l}-0.00 \\
(-0.14 \text { to } \\
0.13)\end{array}$ & $0.10(9 \%)$ & 0.85 \\
\hline
\end{tabular}

$A M A$, aortic microcalcification activity; $L O A$, limits of agreement 

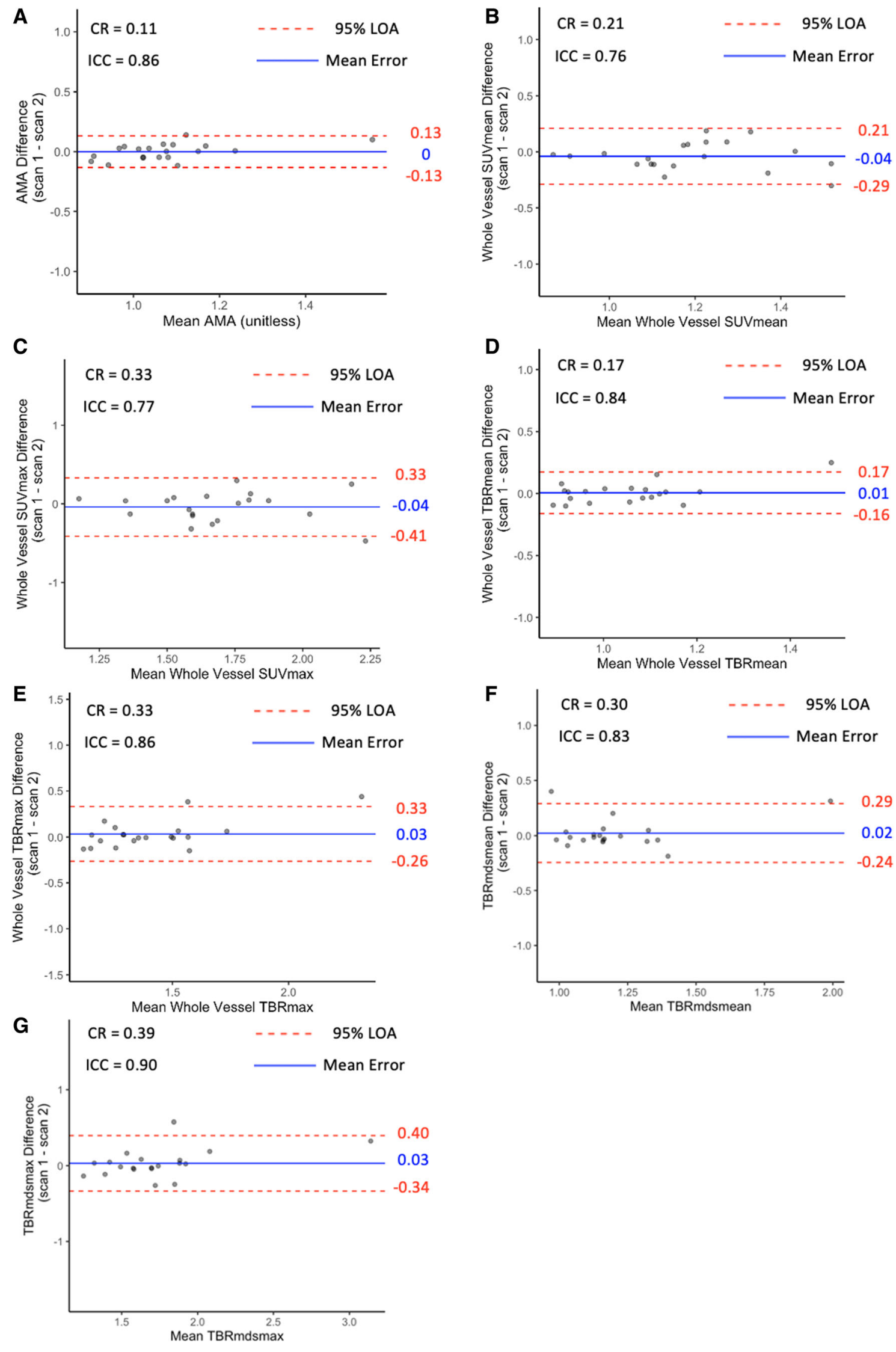

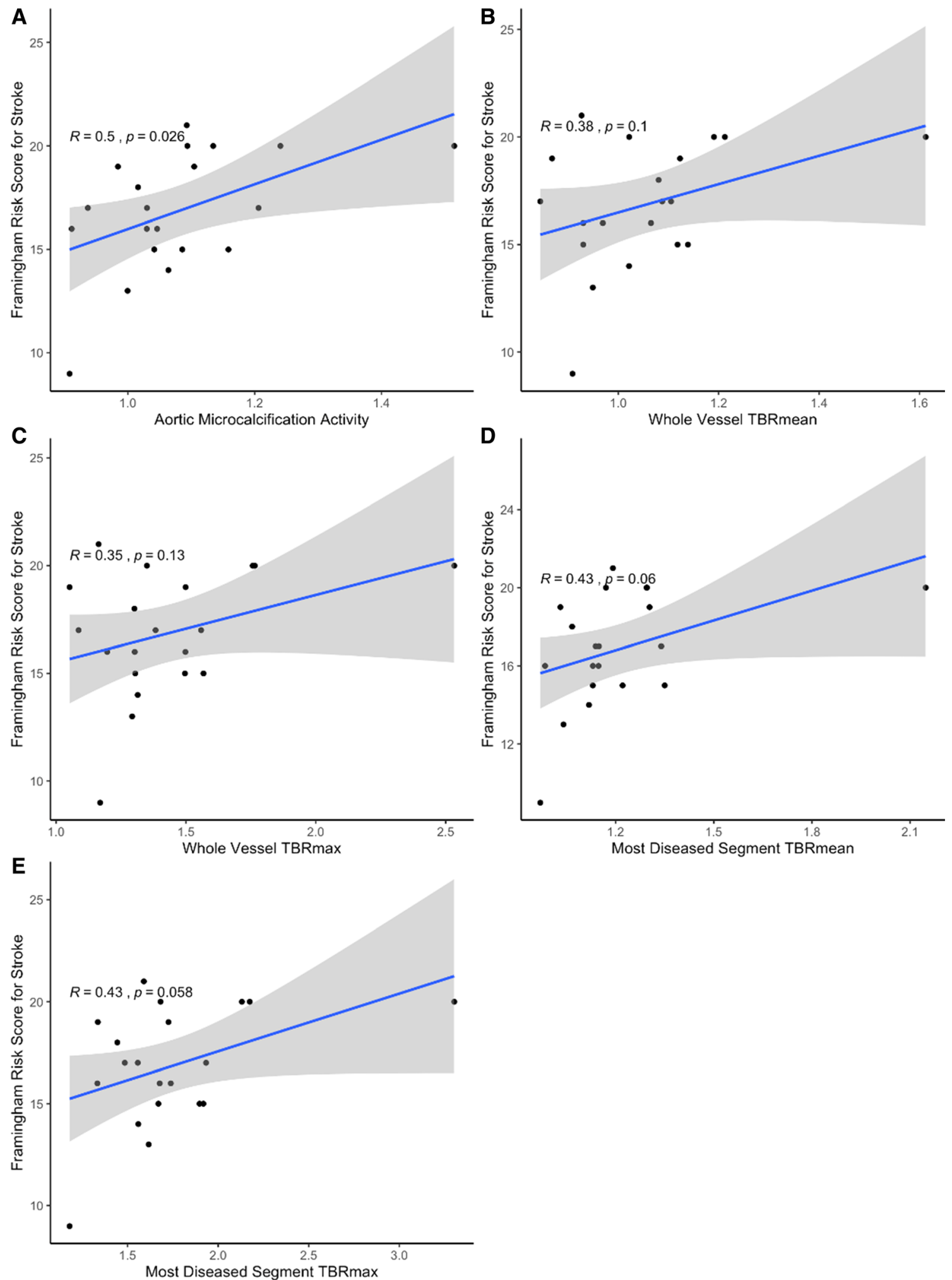

Figure 5. Scatterplots with Pearson's correlation coefficients for the various methods of quantifying ${ }^{18} \mathrm{~F}$-soidum fluoride uptake in the thoracic aorta compared with Framingham Risk Score for stroke in each patient. (A) Aortic macrocalcification activity (B) whole vessel TBRmean (C) whole vessel TBRmax (D) most diseased segment TBRmean (E) most diseased segment TBRmax. AMA, aortic microcalcification activity; TBR tissue to background ratio. 
Table 4. Correlation coefficients between aortic ${ }^{18} \mathrm{~F}$-sodium fluoride quantification methods and clinical risk scores

\begin{tabular}{|c|c|c|c|c|}
\hline & $\begin{array}{l}\text { Framingham } \\
\text { stroke risk } \\
\text { score }\end{array}$ & $\begin{array}{c}\text { Revised } \\
\text { Framingham } \\
\text { stroke risk } \\
\text { score } \\
\text { (10-year risk) }\end{array}$ & $\begin{array}{l}\text { Framingham risk } \\
\text { score for hard } \\
\text { coronary events } \\
\text { (10-year risk) }\end{array}$ & $\begin{array}{l}\text { ACC/AHA } \\
\text { atherosclerotic } \\
\text { cardiovascular } \\
\text { disease score } \\
\text { (10-year risk) }\end{array}$ \\
\hline $\begin{array}{l}\text { Aortic } \\
\text { microcalcification } \\
\text { activity }\end{array}$ & $\mathbf{R}=0.50^{*}$ & $\mathbf{R}=0.44^{*}$ & $\mathbf{R}=0.44^{*}$ & $R=0.33$ \\
\hline $\begin{array}{l}\text { Whole vessel } \\
\text { TBRmean }\end{array}$ & $R=0.38$ & $R=0.22$ & $R=0.21$ & $R=0.11$ \\
\hline $\begin{array}{l}\text { Whole vessel } \\
\text { TBRmax }\end{array}$ & $R=0.35$ & $R=0.27$ & $R=0.32$ & $R=0.20$ \\
\hline $\begin{array}{l}\text { Most diseased } \\
\text { segment } \\
\text { TBRmean }\end{array}$ & $R=0.43$ & $R=0.41$ & $R=0.43$ & $R=0.29$ \\
\hline $\begin{array}{l}\text { Most diseased } \\
\text { segment TBRmax }\end{array}$ & $R=0.43$ & $R=0.36$ & $\mathbf{R}=0.48^{*}$ & $R=0.33$ \\
\hline
\end{tabular}

ACC, American College of Cardiology; AHA, American heart association; TBRmax, maximum tissue to background ratio; TBRmean, mean tissue to background ratio

${ }^{*} P \leq 0.05$

TBRmax values in particular are based upon a small number of highly intense pixels and provide information about the peak intensity of a lesion. On the other hand, AMA incorporates both voxel intensity and volume, providing a global quantification of disease burden. These two approaches may have strengths under differing circumstances. For example, the whole vessel TBRmax and most diseased segment approaches may be more helpful in assessing diseases that are initiated by a threshold effect, such as plaque rupture or aortic dissection. In contrast, other diseases may be best captured by describing the overall burden of disease and AMA, such as aneurysm expansion or aortitis. However, theoretical application of such approaches does have limitations and depends on a number of factors. For example, we recently demonstrated that the summary measure of coronary microcalcification activity was the strongest predictor of future coronary events in patients with multivessel disease. ${ }^{9}$ This probably reflects the fact that plaque rupture commonly heals spontaneously without causing myocardial infarction and therefore a measure of overall disease activity is more powerful than focusing on a single lesion TBRmax. Whether a single intense lesion or overall disease activity better reflects risk of subsequent events in thoracic aortic disease, such as stroke in atherogenic patients or complications of thoracic aneurysm disease, remains to be seen.
In contrast to our findings in the coronary arteries, ${ }^{18}$ background and motion corrections make minimal difference to overall AMA reproducibility. The timedelay blood pool correction accounts for the different elimination rates between the coronary arteries and blood pool seen over time. ${ }^{18,20}$ However, the elimination rates for the aorta over the same periods are different to those seen in the coronaries (Supplemental Figure 3). The time-delay blood pool correction formula used in coronary microcalcification activity should, therefore, not be applied to the AMA measurements. Motion correction is necessary in assessing the uptake in the coronary arteries as they are relatively small vessels, with potential contamination from surrounding structures (e.g. mitral valve annular calcification), partial volume effects and marked movement throughout the cardiac cycle. The aorta, on the other hand, is a large and relatively stationary vessel, with little contamination from surrounding structures and reduced suseptability to potential partial volume effects, although these still may be present. Moreover, our technique for drawing AMA volumes of interest was standardised to $4 \mathrm{~mm}$ beyond the maximal lumen diameter, likely incorporating most aortic movement. This probably explains why motion correction had no effect on AMA values.

It is important to highlight some limitations to our study. Due to well documented problems with spinal contamination influencing accurate ${ }^{18} \mathrm{~F}-\mathrm{NaF}$ assessment 
in the descending thoracic aorta, we chose to limit our AMA analysis to the ascending aorta and aortic arch. Importantly our AMA approach could also be applied to other tracers used to assess disease activity in the aorta (e.g. ${ }^{18}$ F-FDG or ${ }^{68}$ Ga-Dotatate), where such contamination is not an issue and where a global assessment of uptake might also include activity in the descending aorta. Although we have demonstrated the favourable efficiency, reproducibility and repeatability of AMA with positive correlations with clinical risk scores, whether or not AMA will improve the prediction of disease progression and cardiovascular events remains to be seen.

\section{NEW KNOWLEDGE GAINED}

Aortic microcalcification activity is a simple, repeatable and reproducible method for quantifying ${ }^{18} \mathrm{~F}-\mathrm{NaF}$ uptake in the ascending aorta and arch that is significantly and substantially quicker to perform compared with alternative methods and correlates with validated cardiovascular risk scores.

\section{CONCLUSION}

In conclusion, we have provided a detailed description of how to assess global ${ }^{18} \mathrm{~F}-\mathrm{NaF}$ activity across both the ascending aorta and aortic arch using a time efficient approach that demonstrates highly favourable repeatability and reproducibility. Studies assessing the ability of AMA to track disease progression and response to therapy as well as predicting cardiovascular outcomes are now required to validate AMA as a novel biomarker of aortic disease.

\section{Acknowledgements}

Authors have no acknowledgments to declare.

\section{Disclosures}

The authors have no relevant conflicts of interest to declare.

\section{Open Access}

This article is licensed under a Creative Commons Attribution 4.0 International License, which permits use, sharing, adaptation, distribution and reproduction in any medium or format, as long as you give appropriate credit to the original author(s) and the source, provide a link to the Creative Commons licence, and indicate if changes were made. The images or other third party material in this article are included in the article's Creative Commons licence, unless indicated otherwise in a credit line to the material. If material is not included in the article's Creative Commons licence and your intended use is not permitted by statutory regulation or exceeds the permitted use, you will need to obtain permission directly from the copyright holder. To view a copy of this licence, visit http://creativecommons.org/licenses/by/4.0/.

\section{References}

1. Desai MY, Cremer PC, Schoenhagen P. Thoracic aortic calcification: Diagnostic, prognostic, and management considerations. JACC Cardiovasc Imaging 2018;11:1012-26.

2. Kim J, Budoff MJ, Nasir K, Wong ND, Yeboah J, Al-Mallah MH, Shea S, Dardari ZA, Blumenthal RS, Blaha MJ, Cainzos-Achirica M. Thoracic aortic calcium, cardiovascular disease events, and allcause mortality in asymptomatic individuals with zero coronary calcium: The Multi-Ethnic Study of Atherosclerosis (MESA). Atherosclerosis 2017;257:1-8.

3. Cho IJ, Chang HJ, Cho I, Heo R, Lee SE, Shim CY, Hong GR, Chung N. Association of thoracic aorta calcium score with exercise blood pressure response and clinical outcomes in elderly individuals: Differential impact of aorta calcification compared with coronary artery calcification. J Am Heart Assoc 2016;5:e03131.

4. Tison GH, Guo M, Blaha MJ, McClelland RL, Allison MA, Szklo M, Wong ND, Blumenthal RS, Budoff MJ, Nasir K. Multisite extracoronary calcification indicates increased risk of coronary heart disease and all-cause mortality: The Multi-Ethnic Study of Atherosclerosis. J Cardiovasc Comput Tomogr 2015;9:406-14.

5. Criqui MH, Denenberg JO, Ix JH, McClelland RL, Wassel CL, Rifkin DE, Carr JJ, Budoff MJ, Allison MA. Calcium density of coronary artery plaque and risk of incident cardiovascular events. JAMA 2014;311:271-8.

6. Hutcheson JD, Maldonado N, Aikawa E. Small entities with large impact: Microcalcifications and atherosclerotic plaque vulnerability. Curr Opin Lipidol 2014;25:327-32.

7. Derlin T, Richter U, Bannas P, Begemann P, Buchert R, Mester J, Klutmann S. Feasibility of 18F-sodium fluoride PET/CT for imaging of atherosclerotic plaque. J Nucl Med 2010;51:862-5.

8. Irkle A, Vesey AT, Lewis DY, Skepper JN, Bird JL, Dweck MR, Joshi FR, Gallagher FA, Warburton EA, Bennett MR, Brindle KM, Newby DE, Rudd JH, Davenport AP. Identifying active vascular microcalcification by (18)F-sodium fluoride positron emission tomography. Nat Commun 2015;6:7495.

9. Dweck MR, Chow MW, Joshi NV, Williams MC, Jones C, Fletcher AM, Richardson H, White A, McKillop G, van Beek EJ, Boon NA, Rudd JH, Newby DE. Coronary arterial 18F-sodium fluoride uptake: A novel marker of plaque biology. J Am Coll Cardiol 2012;59:1539-48.

10. Kwiecinski J, Tzolos E, Adamson PD, Cadet S, Moss AJ, Joshi N, Williams MC, van Beek EJR, Dey D, Berman DS, Newby DE, Slomka PJ, Dweck MR. Coronary 18F-sodium fluoride predicts outcome in patients with coronary artery disease. J Am Coll Cardiol 2020;75:3061-74.

11. Blomberg BA, de Jong PA, Thomassen A, Lam MGE, Vach W, Olsen MH, Mali WPTM, Narula J, Alavi A, Høilund-Carlsen PF. Thoracic aorta calcification but not inflammation is associated with increased cardiovascular disease risk: Results of the CAMONA study. Eur J Nucl Med Mol Imaging 2017;44:249-58.

12. Blomberg BA, Thomassen A, de Jong PA, Simonsen JA, Lam MG, Nielsen AL, Mickley H, Mali WP, Alavi A, Høilund-Carlsen PF. Impact of personal characteristics and technical factors on quantification of sodium $18 \mathrm{~F}$-fluoride uptake in human arteries: 
Prospective evaluation of healthy subjects. J Nucl Med 2015;56:1534-40.

13. Joshi NV, Toor I, Shah AS, Carruthers K, Vesey AT, Alam SR, Sills A, Hoo TY, Melville AJ, Langlands SP, Jenkins WS, Uren NG, Mills NL, Fletcher AM, van Beek EJ, Rudd JH, Fox KA, Dweck MR, Newby DE. Systemic atherosclerotic inflammation following acute myocardial infarction: Myocardial infarction begets myocardial infarction. J Am Heart Assoc 2015;4:e001956.

14. Wolf PA, D'Agostino RB, Belanger AJ, Kannel WB. Probability of stroke: a risk profile from the Framingham Study. Stroke 1991;22:312-8.

15. D'Agostino RB, Wolf PA, Belanger AJ, Kannel WB. Stroke risk profile: adjustment for antihypertensive medication. The Framingham Study. Stroke 1994;25:40-3.

16. Moss AJ, Doris MK, Andrews JPM, Bing R, Daghem M, van Beek EJR, Forsyth L, Shah ASV, Williams MC, Sellers S, Leipsic J, Dweck MR, Parker RA, Newby DE, Adamson PD. Molecular coronary plaque imaging using $18 \mathrm{~F}$-fluoride. Circ Cardiovasc Imaging 2019;12:e08574.

17. Moss AJ, Dweck MR, Doris MK, Andrews JPM, Bing R, Forsythe RO, Cartlidge TR, Pawade TA, Daghem M, Raftis JB, Williams MC, van Beek EJR, Forsyth L, Lewis SC, Lee RJ, Shah ASV, Mills NL, Newby DE, Adamson PD. Ticagrelor to reduce myocardial injury in patients with high-risk coronary artery plaque. JACC Cardiovasc Imaging 2020;13:1549-60.

18. Lassen ML, Kwiecinski J, Dey D, Cadet S, Germano G, Berman DS, Adamson PD, Moss AJ, Dweck MR, Newby DE, Slomka PJ. Triple-gated motion and blood pool clearance corrections improve reproducibility of coronary. Eur J Nucl Med Mol Imaging 2019;46:2610-20.

19. Doris MK, Otaki Y, Krishnan SK, Kwiecinski J, Rubeaux M, Alessio A, Pan T, Cadet S, Dey D, Dweck MR, Newby DE, Berman DS, Slomka PJ. Optimization of reconstruction and quantification of motion-corrected coronary PET-CT. J Nucl Cardiol 2020;27:494-504.

20. Kwiecinski J, Berman DS, Lee SE, Dey D, Cadet S, Lassen ML, Germano G, Jansen MA, Dweck MR, Newby DE, Chang HJ, Yun M, Slomka PJ. Three-hour delayed imaging improves assessment of coronary. J Nucl Med 2019;60:530-5.

21. Massera D, Doris MK, Cadet S, Kwiecinski J, Pawade TA, Peeters FECM, Dey D, Newby DE, Dweck MR, Slomka PJ. Analytical quantification of aortic valve $18 \mathrm{~F}$-sodium fluoride PET uptake. J Nucl Cardiol 2018;27(3):962-72.

22. Tzolos E, Kwiecinski J, Lassen ML, Cadet S, Adamson PD, Moss AJ, Joshi N, Williams MC, van Beek EJR, Dey D, Berman DS, Dweck MR, Newby DE and Slomka PJ. Observer repeatability and interscan reproducibility of $18 \mathrm{~F}$-sodium fluoride coronary microcalcification activity. J Nucl Cardiol 2020.

23. Kwiecinski J, Cadet S, Daghem M, Lassen ML, Dey D, Dweck MR, Berman DS, Newby DE, Slomka PJ. Whole-vessel coronary 18F-sodium fluoride PET for assessment of the global coronary microcalcification burden. Eur $\mathrm{J}$ Nucl Med Mol Imaging 2020;47:1736-45.

24. Dweck MR, Khaw HJ, Sng GK, Luo EL, Baird A, Williams MC, Makiello P, Mirsadraee S, Joshi NV, van Beek EJ, Boon NA, Rudd JH, Newby DE. Aortic stenosis, atherosclerosis, and skeletal bone: is there a common link with calcification and inflammation? Eur Heart J 2013;34:1567-74.

25. Fayad ZA, Mani V, Woodward M, Kallend D, Abt M, Burgess T, Fuster V, Ballantyne CM, Stein EA, Tardif JC, Rudd JH, Farkouh ME, Tawakol A, Investigators d-P. Safety and efficacy of dalcetrapib on atherosclerotic disease using novel non-invasive multimodality imaging (dal-PLAQUE): a randomised clinical trial. Lancet 2011;378:1547-59.

26. Dufouil C, Beiser A, McLure LA, Wolf PA, Tzourio C, Howard VJ, Westwood AJ, Himali JJ, Sullivan L, Aparicio HJ, KellyHayes M, Ritchie K, Kase CS, Pikula A, Romero JR, D'Agostino RB, Samieri C, Vasan RS, Chêne G, Howard G, Seshadri S. Revised framingham stroke risk profile to reflect temporal trends. Circulation 2017;135:1145-59.

27. Goff DC, Lloyd-Jones DM, Bennett G, Coady S, D'Agostino RB, Gibbons R, Greenland P, Lackland DT, Levy D, O'Donnell CJ, Robinson JG, Schwartz JS, Shero ST, Smith SC, Sorlie P, Stone NJ, Wilson PW, Jordan HS, Nevo L, Wnek J, Anderson JL, Halperin JL, Albert NM, Bozkurt B, Brindis RG, Curtis LH, DeMets D, Hochman JS, Kovacs RJ, Ohman EM, Pressler SJ, Sellke FW, Shen WK, Tomaselli GF, Guidelines ACoCAHATFoP. ACC/AHA guideline on the assessment of cardiovascular risk: a report of the American College of Cardiology/American Heart Association Task Force on Practice Guidelines. Circulation 2013;2014(129):S49-73.

28. Wilson PW, D'Agostino RB, Levy D, Belanger AM, Silbershatz H, Kannel WB. Prediction of coronary heart disease using risk factor categories. Circulation 1998;97:1837-47.

29. Vaz S, Falkmer T, Passmore AE, Parsons R, Andreou P. The case for using the repeatability coefficient when calculating test-retest reliability. PLoS ONE 2013;8:e73990.

Publisher's Note Springer Nature remains neutral with regard to jurisdictional claims in published maps and institutional affiliations. 